\title{
Chronic furosemide administration blunts renal BOLD magnetic resonance response to an acute furosemide stimulus in patients being evaluated for renal artery revascularization
}

\author{
Michael E Hall ${ }^{1 *}$, Michael Rocco ${ }^{2}$, Tim M Morgan ${ }^{3}$, Craig Hamilton ${ }^{4}$, Matthew Edwards ${ }^{5}$, Jennifer Jordan ${ }^{1,4}$, \\ Justin Hurie ${ }^{5}$ W Gregory Hundley ${ }^{1}$
}

From 16th Annual SCMR Scientific Sessions

San Francisco, CA, USA. 31 January - 3 February 2013

\section{Background}

Blood Oxygen Level Dependent (BOLD) magnetic resonance (MR) is a novel imaging tool that is able to detect tissue oxygenation and has recently been utilized to evaluate renal function in patients with renal artery stenosis (RAS). Renal BOLD imaging is typically performed before and after a furosemide stimulus to assess kidney viability. Furosemide blocks the sodium-potassium2chloride transporter, an oxygen-dependent process, in the ascending loop of Henle located in the renal medulla. Presumably, kidneys that are able to decrease oxygen consumption and increase BOLD (T2*) signal in response to furosemide would be viable and benefit from revascularization procedures. A standard dose of $20 \mathrm{mg}$ of intravenous (IV) furosemide is administered to evaluate renal responsiveness (increased $\mathrm{T} 2 *$ signal intensity) and viability. However, little is known about the effect of prior exposure to furosemide on the ability of BOLD MR techniques to evaluate renal function.

\section{Methods}

We performed comprehensive MR evaluations of renal artery blood flow with phase contrast angiography and renal oxygenation with BOLD MR (1.5T Siemens Avanto) on 54 patients referred for abnormal renal arterial Doppler exams. We measured BOLD signal intensity (T2*) in the renal cortex and medulla before and after 20mg IV furosemide administration as per previously published studies. Renal function was assessed

\footnotetext{
${ }^{1}$ Cardiology, Wake Forest School of Medicine, Winston-Salem, NC, USA Full list of author information is available at the end of the article
}

by the CKD-EPI glomerular filtration rate (GFR) calculation. Participants that take furosemide chronically abstained the morning of the MR scan.

\section{Results}

Our study included participants with a wide range of GFR $(21-136 \mathrm{ml} / \mathrm{min}$ per $1.73 \mathrm{~m} 2$, mean $55 \pm 26)$ and age (46-88 years, mean $69 \pm 9$ ). $54 \%$ were women, $32 \%$ were African American and 68\% Caucasian, and 37\% were diabetic. Home furosemide dose ranged from 0 $\mathrm{mg} /$ day to $160 \mathrm{mg} /$ day. $60 \%$ of patients evaluated were furosemide naïve. After controlling for age, GFR, gender, race, renal artery stenosis (\%), and body mass index we evaluated participants' home doses of furosemide to determine if people who are chronically administered furosemide exhibit similar changes in tissue oxygenation as those who do not receive chronic furosemide therapy. Home furosemide dose was an independent, negative predictor of renal medullary $\mathrm{T} 2 *$ response $(\mathrm{p}=0.011)$ in response to a standard $20 \mathrm{mg}$ IV furosemide challenge.

\section{Conclusions}

These data suggest that patients who are chronically administered loop diuretics, especially those receiving large daily doses $(\geq 100 \mathrm{mg} /$ daily), may need a different dosing strategy to accurately detect changes in renal oxygenation in response to a furosemide stimulus with BOLD MR. These findings are particularly important in this patient population because patients who are chronically administered furosemide (common in patients with RAS) may be misclassified as having nonviable kidneys 
Table 1 In a study of 54 patients evaluated for renal artery stenosis by BOLD MRI before and after furosemide administration, only race and total daily dose of lasix were independent predictors of changes in renal oxygenation.

\begin{tabular}{ccccc}
\hline Effect & & Estimate & Standard Error & p-value \\
\hline Intercept & & 4.8 & 2.1 & 0.57 \\
\hline Region & Cortex & -4.3 & 2.2 & 0.063 \\
\hline Kidney & Left & 0.68 & 2.7 & 0.81 \\
\hline Gender & Men & -2.0 & 2.9 & 0.95 \\
\hline Race & AA & 7.2 & 3.21 & 0.038 \\
\hline Age (years) & & 0.067 & 0.23 & 0.77 \\
\hline GFR (ml/min/ 1.73m ${ }^{2)}$ & & -0.014 & 0.062 & 0.83 \\
\hline Stenosis (\%) & & -0.087 & 0.062 & 0.076 \\
\hline BMl (kg/m ${ }^{2)}$ & & 0.060 & 0.23 & 0.80 \\
\hline Lasix dose $(\mathrm{mg} /$ day) & & -0.087 & 0.03 & 0.011 \\
\hline
\end{tabular}

due to an attenuated $\mathrm{T} 2 *$ signal intensity increases assessed with BOLD MR.

\section{Funding}

R42 AG030248 NIH (Hundley)

\section{Author details}

${ }^{1}$ Cardiology, Wake Forest School of Medicine, Winston-Salem, NC, USA.

${ }^{2}$ Nephrology, Wake Forest School of Medicine, Winston-Salem, NC, USA ${ }^{3}$ Biostatistical Sciences, Wake Forest School of Medicine, Winston-Salem, NC, USA. ${ }^{4}$ Biomedical Engineering, Wake Forest School of Medicine, WinstonSalem, NC, USA. ${ }^{5}$ Vascular Surgery, Wake Forest School of Medicine, WinstonSalem, NC, USA.

Published: 30 January 2013

doi:10.1186/1532-429X-15-S1-P238

Cite this article as: Hall et al:: Chronic furosemide administration blunts renal BOLD magnetic resonance response to an acute furosemide stimulus in patients being evaluated for renal artery revascularization. Journal of Cardiovascular Magnetic Resonance 2013 15(Suppl 1):P238.

Submit your next manuscript to BioMed Central and take full advantage of:

- Convenient online submission

- Thorough peer review

- No space constraints or color figure charges

- Immediate publication on acceptance

- Inclusion in PubMed, CAS, Scopus and Google Scholar

- Research which is freely available for redistribution

Submit your manuscript at www.biomedcentral.com/submit 